\title{
PENERAPAN TEKNOLOGI AUGMENTED REALITY PADA KATALOG RUMAH BERBASIS ANDROID (STUDI KASUS PT. JASHANDO HAN SAPUTRA)
}

\author{
Muntahanah $^{1}$, Rozali Toyib ${ }^{2}$, Miko Ansyori ${ }^{3}$ \\ ${ }^{123}$ Informatika, Fakultas Teknik Universitas Muhamamadiyah Bengkulu \\ Jl.Bali PO.Box 118 Kota Bengkulu 38119 INDONESIA \\ (TELP 0736-22765 Fax. 0736-26161) \\ ${ }^{1}$ hanna.umb@gmail.com \\ ${ }^{2}$ rozalitoyib@gmail.com \\ ${ }^{3}$ mikoansyori@gmail.com
}

\begin{abstract}
Abstrak: Bisnis properti sudah menjamur di kota-kota saat ini, terutama di kota Bengkulu sendiri. Karena banyaknya permintaan akan kebutuhan rumah, banyak produsen yang menjalani bisnis ini. Perkembangan teknologi pun semakin pesat seperti mobile android, bisa kita manfaatkan perkembangan teknologi ini untuk media pemasaran yang iteraktif khusus nya pemasaran rumah.Augmented Reality (AR) adalah salah satu perkembangan teknologi saat ini.Augmented Reality (AR), adalah teknologi yang menggabungkan benda maya dua dimensi dan tiga dimensi kedalam sebuah lingkungan nyata tiga dimensi lalu memproyeksikan benda-benda maya tersebut dalam waktu nyata. Penelitian ini akan menerapkan teknologi AR kedalam katalog rumah berbasis android. AR Katalog rumah berbasis andoid ini memerlukan video streaming yang diambil dari kamera sebagai sumber masukkan, kemudian aplikasi ini akan melacak dan mendeteksi marker (penanda) dengan menggunakan sistem tracking, setelah marker dideteksi, model rumah 3D muncul di atas marker seolah-olah model tersebut nyata. Untuk membuat model rumah ini, model harus dibuat terlebih dahulu dengan menggunakan perangkat lunak untuk membuat objek 3D, dalam kasus ini menggunakan sweethome3D. Pengujian aplikasi ini dilakukan menggunakan kamera handphone 5MP, menggunakan 2 jenis marker, dan seluruh proses dari pembuatan aplikasi ini menggunakan Unity 3D. Dari hasil pengujian, aplikasi ini berjalan dengan baik ketika jarak $27 \mathrm{~cm}$ dengan sudut pandang $45^{\circ}$ dan memiliki cahaya yang cukup. Itu merupakan proses tracking yang ideal.
\end{abstract}

Kata Kunci: Property, Housing, Manufacture, Augment Reality, 3D

\begin{abstract}
The property business has mushroomed in cities today, especially in the city of Bengkulu yourself. Due to the large demand for housing needs, many manufacturers are doing business. Technological developments even more rapidly as the mobile android, we can use this technology for the development of marketing media marketing its specialty iteraktif rumah.Augmented Reality (AR) is a technology development ini.Augmented Reality (AR), is a technology that combines virtual objects twodimensional and three-dimensional into a real three-dimensional environment and then projecting the virtual objects in real time. This study will apply AR technology into Androidbased home catalog. AR catalog home based andoid requires streaming videos taken from the
\end{abstract}

camera as the source input, then this app will track and detect the marker (marker) by using the tracking system, after the marker is detected, the model of 3D home appear above the marker as if the model is real, To make this house model, the model must be made in advance by using software to create $3 D$ objects, in this case using sweethome3D. This application testing is done using a 5MP camera phone, using two types of marker, and the whole process of making this application using Unity 3D. From the test results, this application runs fine when the distance of $27 \mathrm{~cm}$ with $45^{\circ}$ viewpoint and have enough light. It is an ideal tracking process. 


\section{PENDAHULUAN}

Rumah merupakan tempat berlindung dan beristirahat serta tempat berkumpul bagi keluarga. Tidak pandang bulu apakah mereka termasuk golongan kaya (golongan menengah keatas) maupun mereka yang termasuk dalam golongan miskin (golongan menengah kebawah) pasti membutuhkan perumahan bagi kehidupannya [1]. Dan pastinya orang menginginkan tempat tinggalnya harus nyaman, dari segi lingkungan, bentuk, desain, dan ukuran.Orang biasanya menginginkan lokasi yang ideal untuk kenyaman, seperti di pergunungan atau di perdesaan yang masih asri.untuk melihat kelokasi rumah, terkadang konsumen tidak memiliki waktu dikarenakan memiliki aktivitas yang padat, terutama orang yang super sibuk, apa lagi lokasi rumah tersebut jaraknya jauh dari lokasi konsumen. Dan juga karena rumah yang ditampilkan dari katalog tersebut belum terlihat detail dan nyata.

Bisnis properti saat ini semakin menunjukkan perkembangan yang pesat.Hal ini dapat dilihat dari meningkatnya permintaan pasar terhadap bisnis properti. Seiring dengan tingginya permintaan pasar berbanding lurus dengan banyaknya perusahaan yang menawarkan produknya dengan menggunakan berbagai macam cara baik dengan menggunakan bunga kredit yang sangat kecil ataupun melakukan pemasaran melalui media komunikasi baik cetak ataupun elektronik. Melalui media promosi tersebut tidak jarang calon pembeli masih merasa bingung untuk membayangkan gambaran atau bentuk rumah yang akan dibangun, karena promosi masih menggunakan objek dua dimensi (2D), yang mempunyai sudut pandang terbatas. Sehingga terkadang pembeli harus mendatangi kantor pemasaran untuk mendapatkan informasi ataupun gambaran yang lebih jelas [1].

Berdasarkan latar belakang di atas, maka penulis mengangkat judul "Penerapan Teknologi Augmented Reality Pada katalog Rumah Berbasis Android”.

\section{LANDASAN TEORI}

\section{A. Rumah}

Menurut Johan Silas [1] rumah mengandung pengertian:

1. Sebagai tempat penyelenggaraan kehidupan dan penghidupan keluarga; rumah harus memenuhi kebutuhan yang bersifat biologis seperti makan, belajar, dan lain-lain, juga memenuhi kebutuhan non biologis, seperti bercengkrama dengan anggota keluarga atau dengan tetangga.

2. Rumah berfungsi sebagai sarana investasi; rumah mempunyai nilai investasi yang bersifat moneter yang dapat diukur dengan uang dan non moneter yang tidak dapat diukur dengan uang., tetapi lebih pada keuntungan moral dan kebahagiaan keluarga.

3. Rumah sebagai sarana berusaha; melalui rumah penghuni dapat meningkatkan pendapatannya guna kelangsungan hidupnya.

4. Rumah sebagai tempat bernaung harus memenuhi kebutuhan ruang akan kegiatan bagi penghuninya. Terdapat beberapa ruang pokok yang ada pada sebuah rumah, yaitu ruang tidur, ruang belajar atau ruang kerja, ruang keluarga, ruang services seperti dapur, dan teras atau ruang tamu. Makna yang terkandung didalam kebutuhan ruangruang tersebut mencerminkan bahwa rumah 
adalah tempat untuk istirahat, tempat untuk mengaktualisasikan diri guna meningkatkan mutu kehidupan, rumah sebagai tempat sosialisasi utamanya dengan keluarga, rumah sebagai tempat menyediakan kebutuhan jasmani dan rohani, serta rumah sebagai tempat bernaung [1].

\section{B. Katalog Rumah}

Katalog berasal dari bahasa Latin catalogus yang beraarti daftar barang atau benda yang disusun untuk tujuan tertentu. Menurut Magetsari [2] catalog adalah daftar buku, peta atau bahan lainnya yang disusun menurut aturan tertentu; pada daftar tersebut dicatat, diberikan, dan diindeks bahan pustaka yang terdapat dalam koleksi satu atau beberapa perpustakaan. Catalog berbeda dengan: (a) semabarang daftar yang disusun tanpa mengikuti aturan baku dan mungkin juga tidak lengkap; (b) bibliografi yang belum tentu mencakupi koleksi tertentu, atau koleksi beberapa perpustakaan. Setiap entri katalog memuat nomor kelas atau nomor panggilan [2].

Fungsi katalog adalah :

1. Memudahkan user dalam retrieval bahan pustaka yang dibutuhkan berdasarkan informasi yang mereka ketahui, bisa berupa judul, pengarang, maupun berdasarkan bidang ilmu yang diperlukan.

2. Untuk menunjukkan apakah perpustakaan memiliki buku yang dikarang oleh pengarang tertentu, mengenai subjek tertentu dan dalam bentuk tertentu.

3. Sebagai wakil ringkas dari bahan pustaka yang dimiliki perpustakaan.

\section{Augmented Reality}

Augmented Reality adalah teknologi yang menggabungkan benda maya dua dimensi dan ataupun tiga dimensi ke dalam sebuah lingkungan nyata tiga dimensi lalu memproyeksikan bendabenda maya tersebut dalam waktu nyata.Tidak seperti realitas maya yang sepenuhnya menggantikan kenyataan, namun Augmented Reality hanya menambahkan atau melengkapi kenyataan.

Riset Augmented Reality bertujuan untuk mengembangkan teknologi yang memperbolehkan penggabungan secara real-time terhadap digital content yang dibuat oleh komputer dengan dunia nyata.Augmented Reality memperbolehkan pengguna melihat objek maya tiga dimensi yang diproyeksikan terhadap dunia nyata. Menurut Azuma [3] (Emerging Technologies of Augmented Reality: Interfaces and Design).Augmented Reality pada dasarnya adalah sebuah konsep yang mencitrakan gambar tiga dimensi yang seolah nyata. Proses ini bisa diperinci menjadi beberapa proses dan komponen. Untuk mencitrakan gambar tiga dimensi tersebut, sistem Augmented Reality terlebih dahulu harus melakukan penglihatan atau vision terhadap lingkungan yang padanya akan dicitrakan objek virtual. kemudian, dilakukanlah proses tracking terhadap objek spesifik yang menentukan letak citraan objek virtual tersebut. Kemudian, objek tersebut akan dikenali, atau dianalisis. Setelah dikenali dan dianalisis posisi dan orientasinya, maka komputer akan melakukan proses pencitraan objek tersebut, dan akan tampak pada perlengkapan display [3].

\section{Markerless Augmented Reality}

Salah satu metode Augmented Reality yang saat ini sedang berkembang adalah metode Markerless Augmented Reality, dengan metodeini pengguna tidak perlu lagi menggunakan sebuah marker untuk menampilkan elemen-elemen digital [4]. Seperti yang saat ini dikembangkan oleh 
perusahaan Augmented Reality terbesar di dunia Total Immersion dan Qualcomm, mereka telah membuat berbagai macam teknik MarkerlessTracking sebagai teknologi andalan mereka, seperti Face Tracking, 3DObject Tracking, dan Motion Tracking [4].

\section{E. Vuforia SDK}

Vuforia adalah Augmented Reality Software Development Kit (SDK) untuk perangkat mobile yang memungkinkan pembuatan aplikasi Augmented Reality.Dulunya lebih dikenal dengan QCAR (Qualcomm Company Augmentend Reality). Ini menggunakan teknologi ComputerVision untuk mengenali dan melacak gambar planar (Target Image) dan objek 3D sederhana, seperti kotak, secara realtime.Kemampuan registrasi citra memungkinkan pengembang untuk mengatur posisi dan virtual orientasi objek, seperti model 3D dan media lainnya, dalam kaitannya dengan gambar dunia nyata ketika hal ini dilihat melalui kamera perangkat mobile. Obyek maya kemudian melacak posisi dan orientasi dari gambar secara real-time sehingga perspektif pengguna pada objek sesuai dengan perspektif mereka pada Target Image, sehingga muncul bahwa objek virtual adalah bagian dari adegan dunia nyata (Mario Fernando rentor, Qualcomm, 2012) [5].

\section{F. Android}

Android adalah sistem operasi untuk telepon mobile yang berbasis Linux yang mencakup sistem opersi, middleware dan aplikasi.Android mereka sendiri untuk digunakan oleh bermacam menyediakan platform terbuka bagi para pengembang untuk menciptakan aplikasi peranti bergerak.Awalnya, Google Inc. membeli Android Inc., pendatang baru yang membuat peranti lunak untuk ponsel. Kemudian untuk mengembangkan Android, dibentuklah Open Handset Alliance, konsorsium dari 34 perusahaan peranti keras, peranti lunak, dan telekomunikasi, termasuk Google, HTC, Intel, Motorola, Qualcomme, TMobile, dan Nvidia [6].

\section{METODE PENELITIAN}

\section{A. Tempat dan Waktu}

Penelitian akan dilakukan di Kantor PT. Jeshando Han Saputra di JL.Lintas bengkulu, desa tebat monok, kabupaten kepahiang, pelaksanaan penelitian direncanakan selama 5 bulan.

\section{B. Teknik Pengumpulan Data}

Menggunakan observasi untuk melihat secara langsung ke tempat penelitian dalam ini PT. Jeshando Han Saputra yang bergerak dalam bidang Proferti kemudian melakukan interview secara langsung kepada pihak yang berhubungan dengan objek yang teliti untuk menggali kebutuhan sistem dan kemudian mencari literature yang berhubungan kasus yang diangkat.

\section{Desain Penelitian \\ Pada penelitian ini dibuat suatu desain penelitian pada Gambar 1.}




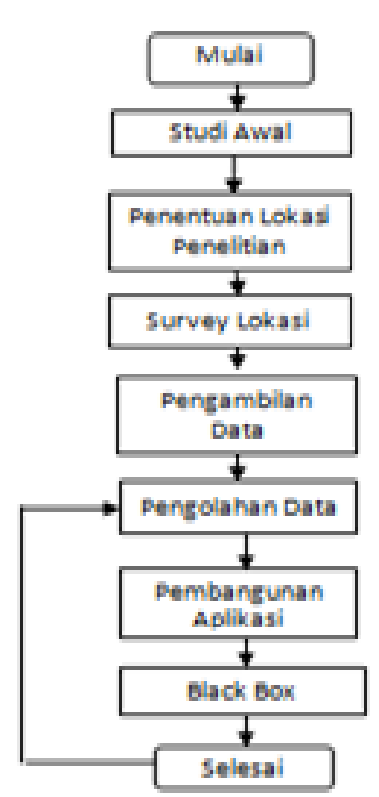

Gambar 1. Desain Penelitian

\section{Desain Flowchart Aplikasi}

Flowchart adalah penggambaran secara grafik dari langkah-langkah dan urut-urutan prosedur dari suatu program. Flowchart membantu programmer untuk memecahkan masalah kedalam segmensegmen yang lebih kecil dan menolong dalam menganalisis alternatif-alternatif lain dalam pengoperasian.

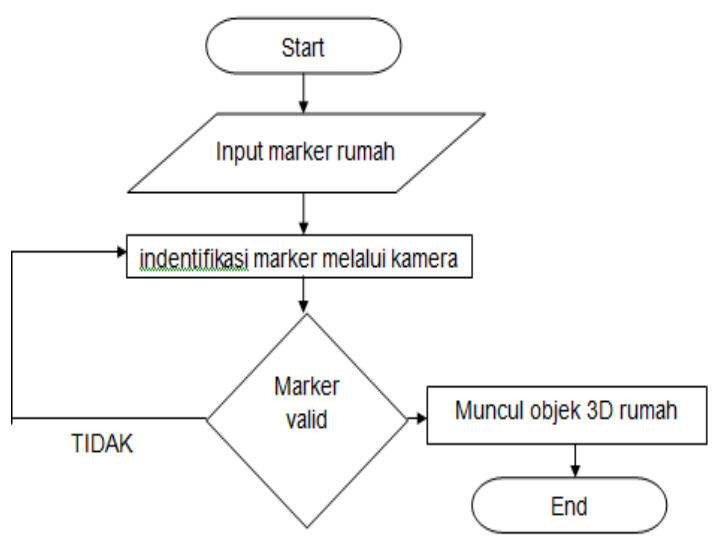

Gambar 2. Flowchart Augmented Reality

\section{E. Model Sekuensial}

Model sekuensial linear mengusul sebuah pendekatan pengembangan perangkat lunak yang sistematik dan sekuensial mulai dari system level dan terus maju ke analis, desain, implementasi dan pengujian. Model sekuensial linear melingkupi aktivitas sebagai berikut:

1. Requirement (analisis kebutuhan).

Mengumpulkan kebutuhan secara lengkap kemudian kemudian dianalisis dan didefinisikan kebutuhan yang harus dipenuhi oleh program yang akan dibangun. Fase ini harus dikerjakan secara lengkap untuk bisa menghasilkan desain yang lengkap.

\section{Design}

Desain dikerjakan setelah kebutuhan selesai dikumpulkan secara lengkap.

\section{Code}

Desain program diterjemahkan ke dalam kode-kode dengan menggunakan bahasa pemrograman yang sudah ditentukan. Program yang dibangun langsung diuji baik secara unit.

4. Test

Penyatuan unit-unit program kemudian diuji secara keseluruhan (system testing).

\section{HASIL DAN PEMBAHASAN}

A. Hasil

1. Pembuatan Objek Rumah

Objek ini terdiri dari beberapa objekyang nanti akan di kembangkan hingga menjadi sebuah objek rumah yang utuh: 


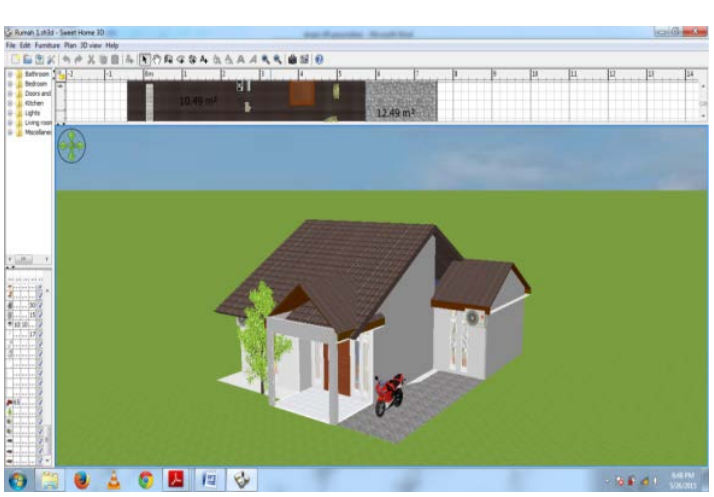

Gambar 3. Objek Rumah

\section{Membuat marker}

Marker adalah suatu penanda yang membuat objek 3D tampil pada tampilan kertas dilayar handphone. Untuk membuat marker dapat menggunakan aplikasi paint atau photoshop, dan kita dapat membuat nya dari gambar yang ada.

Setelah pembuatan marker ini selesai, agar marker dapat dikenali oleh aplikasi unity 3D nya, langkah selanjutnya adalah mengupload marker yang sudah dibuat. Agar marker ini dapat dikenali oleh aplikasi augmented realitynya.

Berikut ini adalah langkah-langkah nya:

1. Untuk mengupload marker buka situs http://develover.vuforia.com dan pastikan anda telah login. Jika anda belum memiliki akun anda dapat melakukan registrasi dahulu.

2. Download marker dalam bentuk 'unity editor' karna anda akan menggunakan unity untuk membuat project $A R$ kemudian file marker anda dalam bentuk *.unitypackage yang siap diimport ke unity.

\section{Download Dataset}

2 of 2 active targets will be downloaded

\section{Name:}

skripsiAR

Select a development platform:

SDK (Eclipse, Ant, Xcode, etc.)

6. Unity Editor

3. Indetifikasi Marker Melalui Kamera

Uji coba aplikasi dilakukan setelah menghasilkan *apk dan mencopy atau menjalankan pada Smartphone ini. Setelah itu install*.apk. pada smartphone yang berhasil diinstall bisa pilih menu start dan langsung arahkan kamera ke marker makaa akan terlihat semua animasi objek yang kita buat.

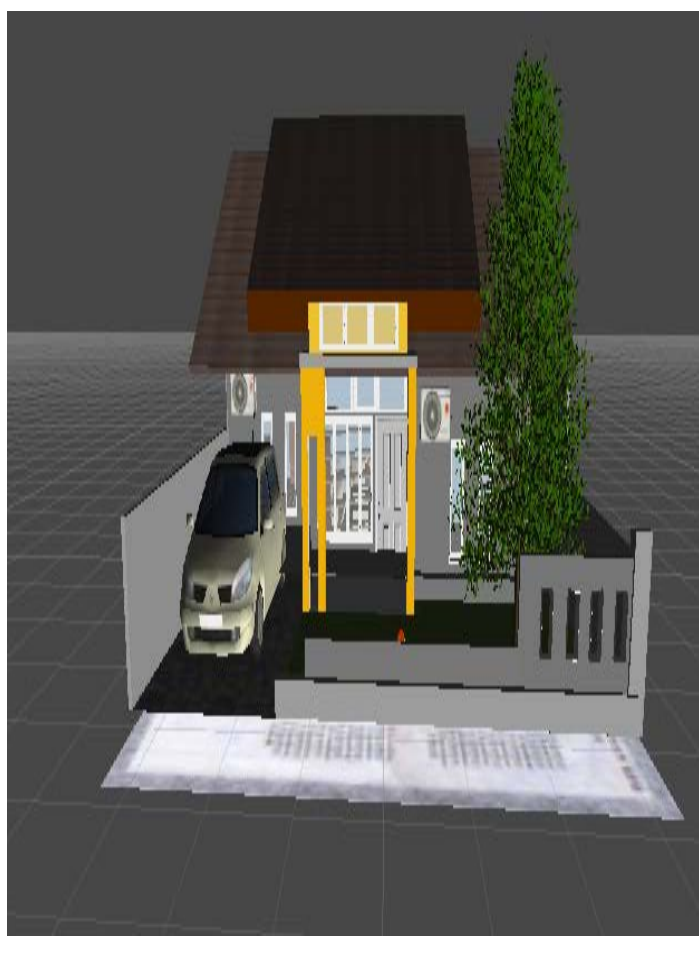

Gambar 5. Tampilan Objek Bagian Depan 
Jurnal Pseudocode, Volume IV Nomor 1, Februari 2017, ISSN 2355-5920

www.ejournal.unib.ac.id/index.php/pseudocode

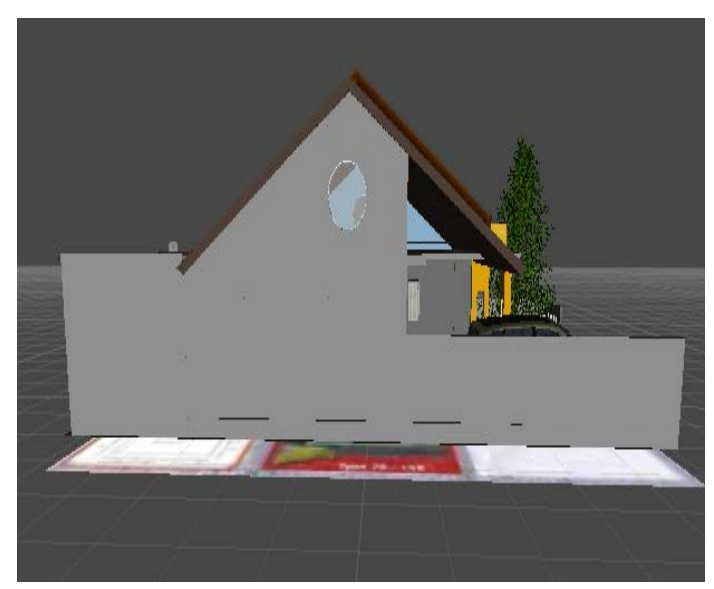

Gambar 6. Tampilan Objek Bagian Samping

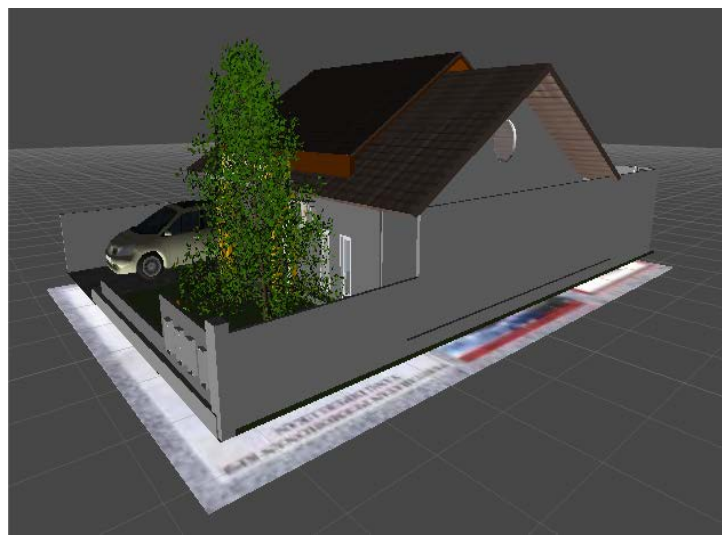

Gambar 7. Tampilan Objek Bagian Sudut
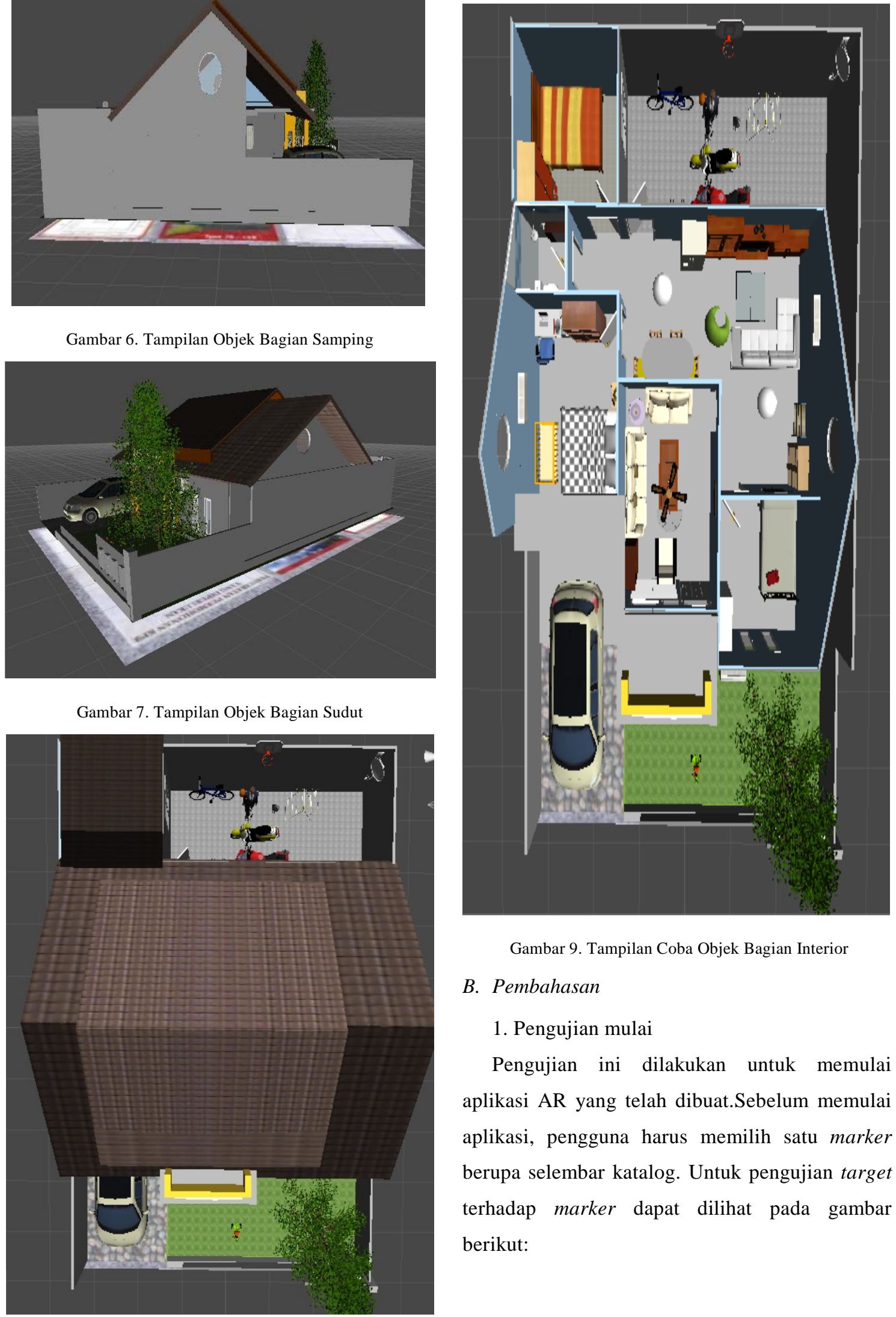

Gambar 9. Tampilan Coba Objek Bagian Interior

\section{B. Pembahasan}

\section{Pengujian mulai}

Pengujian ini dilakukan untuk memulai aplikasi AR yang telah dibuat.Sebelum memulai aplikasi, pengguna harus memilih satu marker berupa selembar katalog. Untuk pengujian target terhadap marker dapat dilihat pada gambar berikut:

Gambar 8. Tampilan Objek Atas 
Jurnal Pseudocode, Volume IV Nomor 1, Februari 2017, ISSN 2355-5920 www.ejournal.unib.ac.id/index.php/pseudocode
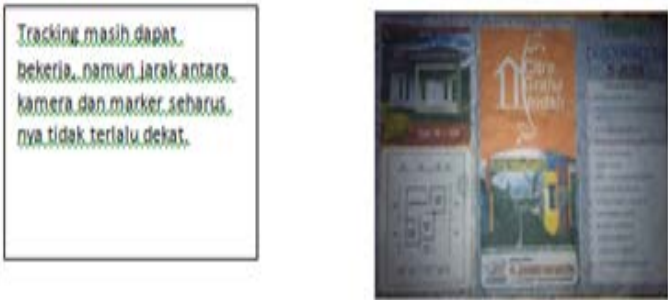

Tampilanideal pada proses
trackine, dengan sudut
pandang $45^{\circ}$ dan target
terlihat seluruh nya

Pada sudut pandang ini $60^{\circ}$, kemungkin tracking massih bias bekerja

Pads sudut pandang kurang dari $70^{\circ}$, disini kemungoinan besat tracking tioak dapat beherjo

Gambar 10. Posisi Target dari Sudut Pandang Kamera

Sedangkan untuk pengujian jarak kamera dan marker, pantulan cahaya dan sudut kemiringan kamera dapat dilihat pada table berikut.
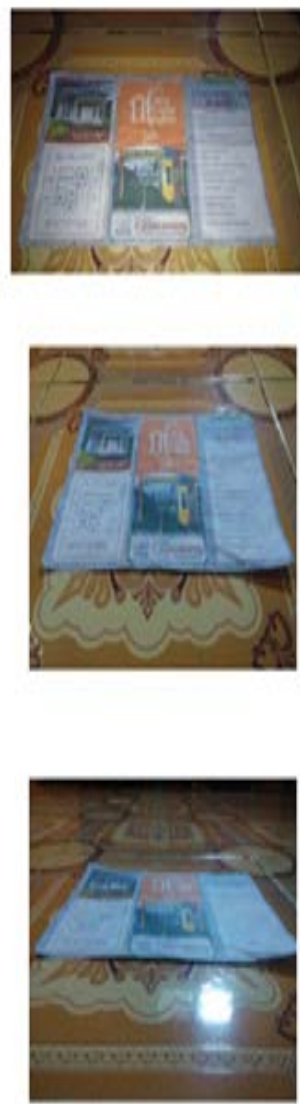

Tabel 1. Pengujian Jarak, Kamera dan Marker

Hasil Pengujan hubungan jarak antara kamera dan marker, pantulan cahaya dan sudut kemiringan kamera

\begin{tabular}{l|l|l|l|l}
\hline Jarak & Sudut & Pencahayaan (cahaya lampu, Tingkat
\end{tabular}

(cm) kemiringan $\quad$ sinar matahan, berawan, gelap) keberhasitan \begin{tabular}{|c|c|c|c} 
& kamera & & \\
\hline 4 & $0^{0}$ & Cahaya lampu, gelap & Tidak berhasi \\
\hline
\end{tabular}

\begin{tabular}{|c|c|c|c|}
\hline 4 & Canaya tampu, getap & Tidak bernasi \\
\hline 4 & $0^{0}$ & Sinar matahari, berawan & Tidak berhasil \\
\hline 8 & $0^{\circ}$ & Cahaya tampu, gelap & Tidak berhasil \\
\hline
\end{tabular}

\begin{tabular}{|c|c|c|r|}
\hline 8 & $0^{\circ}$ & Cahaya lampu, gelap & Tidak berhas \\
\hline 8 & $0^{0}$ & Sinar matahari, berawan & Berhasil \\
\hline
\end{tabular}

\begin{tabular}{|c|c|c|c|}
\hline 12 & $0^{\circ}$ & Cahaya Lampu, gelap & Tidak berhasi \\
\hline 12 & $0^{0}$ & Sinar matahari, berawan & Berhasil \\
\hline
\end{tabular}

\begin{tabular}{|c|c|c|c|}
\hline 27 & $0^{0}$ & Cahaya lampu, gelap & Tidak berhasii \\
\hline 27 & $0^{\circ}$ & Sinar matahan, berawan & Berhasil \\
\hline 50 & $0^{0}$ & Cahaya lampu, gelap & Tidak berhasii \\
\hline 50 & $0^{\circ}$ & Sinar matahan, berawan & Berhasil \\
\hline 4 & $45^{\circ}$ & Cahaya Lampu, gelap & Tidak berhasil \\
\hline 4 & $45^{\circ}$ & Sinar mahari, Derawan & Tidak bethasit \\
\hline
\end{tabular}

\begin{tabular}{|c|c|c|c|}
\hline 4 & $45^{\circ}$ & Sinar matahari, berawan & Tidak bethasil \\
\hline 8 & $45^{\circ}$ & Cahaya lampu, gelap & Tidak bethasil \\
\hline 8 & $45^{\circ}$ & Sinar matahari, berawan & Berhasil \\
\hline 12 & $45^{\circ}$ & Cahaya Lampu, gelap & Tidak berhasil \\
\hline 12 & $45^{\circ}$ & Sinar matahari, berawan & Berhasil \\
\hline 27 & $45^{\circ}$ & Cahaya lampu, gelap & Tidak berhasil \\
\hline 27 & $45^{\circ}$ & Sinar matahari, berawan & Tidak berhasil \\
\hline 50 & $45^{\circ}$ & Cahaya lampu, gelap & Tidak berhasil \\
\hline 50 & $45^{\circ}$ & Sinar matahari, berawan & Berhasil \\
\hline 4 & $70^{\circ}$ & Cahaya lampu, gelap & Tidak berhasil \\
\hline 4 & $70^{\circ}$ & Sinar matahari, berawan & Tidak berhasil \\
\hline 8 & $70^{\circ}$ & Cahaya lampu, gelap & Tidak berhasil \\
\hline 8 & $70^{\circ}$ & Sinar matahari, berawan & Berhasil \\
\hline 8 & $70^{\circ}$ & Sinar matahari, berawan & Berhasil \\
\hline 12 & $70^{\circ}$ & Cahaya lampu, gelap & Tidak berhasil \\
\hline 12 & $70^{\circ}$ & Sinar matahari, berawan & Berhasil \\
\hline 27 & $70^{\circ}$ & Cahaya lampu, gelap & Tidak berhasil \\
\hline 27 & $70^{\circ}$ & Sinar matahari, berawan & Berhasil \\
\hline 50 & $70^{\circ}$ & Cahaya lampu, gelap & Tidak berhasil \\
\hline 50 & $70^{\circ}$ & Sinar matahari, berawan & Berhasil \\
\hline
\end{tabular}

Tabel 2. Pengujian Jarak, Sudut Kemiringan, dan Cahaya

\begin{tabular}{|c|c|c|c|c|}
\hline \multicolumn{2}{|c|}{ pengujian } & Baik & Sedang & buruk \\
\hline Jarak (cm) & 4 & - & - & $\checkmark$ \\
\cline { 2 - 5 } & 8 & - & - & $\checkmark$ \\
\cline { 2 - 5 } & 12 & - & $\checkmark$ & - \\
\cline { 2 - 5 } & 27 & $\checkmark$ & - & - \\
\cline { 2 - 5 } & 50 & - & $\checkmark$ & - \\
\hline \multirow{4}{*}{$\begin{array}{c}\text { Sudut } \\
\text { kemiringan }\end{array}$} & $0^{\circ}$ & - & $\checkmark$ & - \\
\cline { 2 - 5 } & $45^{\circ}$ & $\checkmark$ & - & - \\
\cline { 2 - 5 } & $70^{\circ}$ & - & $\checkmark$ & - \\
\hline Cahaya & ya & $\checkmark$ & - & $\checkmark$ \\
\cline { 2 - 5 } & tidak & - & - & \\
\hline
\end{tabular}

Hasil pengujian terhadap marker dan kamera agar augmented reality muncul dapat dilihat pada table 4.2. pengujian dilakukan dengan jarak $4 \mathrm{~cm}$, $8 \mathrm{~cm}, 12 \mathrm{~cm}, 27 \mathrm{~cm}, 50 \mathrm{~cm}$ dan dipengaruhi cahaya dan kemiringan kamera. Jarak minimum marker terhadap kamera yaitu $50 \mathrm{~cm}$ dengan sudut minimum $0^{0}$ dan sudut maksimum $70^{\circ}$. Jarak 
minimum dan maksimum serta sudut kemiringan kamera minimum - maksimum diperngaruhi oleh cahaya, dimana dalam pengujian apabila ada pantulan cahaya maka augmented reality (3d rumah) tidak akan muncul.

Tabel 3. Hasil Pengujian

\begin{tabular}{|c|l|c|l|}
\hline \multicolumn{4}{|c|}{ Kasus dan hasil uji (data normal) } \\
\hline Data masukkan & \multicolumn{1}{|c|}{ Yang diharapkan } & Pengamatan & kesimpulan \\
\hline Klik menu mulai & Ketika meng-klik & Augmented & diterima \\
& menu mulai & reality (3d & \\
& menampilkan & rumah) & \\
& augmented reality & muncul tepat & \\
& (3d rumah) diatas & diatas marker & \\
& marker & & \\
\hline
\end{tabular}

1. Pengujian Panduan

Pengujian ini dilakukan untuk menampilknan informasi dan panduan yang berada di dalam aplikasi.

Tabel 4. Kasus dan Hasil Uji Menu Panduan

\begin{tabular}{|l|l|l|l|}
\hline \multicolumn{3}{|c|}{ Kasus dan hasil uji (data normal) } \\
\hline Data masukkan & Yang diharapkan & Pengamatan & Kesimpulan \\
\hline $\begin{array}{l}\text { Klik menu } \\
\text { "panduan" }\end{array}$ & $\begin{array}{l}\text { Melihat panduan } \\
\text { cara } \\
\text { menggunakan } \\
\text { aplikasi AR }\end{array}$ & & \\
\hline
\end{tabular}

\section{Pengujian Keluar}

Pengujian dini dilakukan untuk mengetahui apakan menu saat diklik apakah keluar dari aplikasi atau tidak.

Tabel 5. Kasus dan Hasil Uji Menu Keluar

\begin{tabular}{|l|l|l|l|}
\hline \multicolumn{3}{|l|}{ Kasus dan hasil uji (data normal) } \\
\hline Data masukkan & Yang diharapkan & Pengamatan & Kesimpulan \\
\hline Klik menu & Keluar dari & Keluar dari & Diterima \\
"keluar" & aplikasi & aplikasi & \\
\hline
\end{tabular}

\section{KESIMPULAN DAN SARAN}

\section{A. Kesimpulan}

1. Dengan adanya sistem aplikasi augmented reality untuk media promosi visual perumahan dapat mempermudah penjual untuk memperkenal kan produk serta mempermudah pembeli untuk memilih rumah yang diinginkan.

2. Jarak dalam proses tracking yang baik: $27 \mathrm{~cm}$, sedang : $8-27 \mathrm{~cm}$, buruk: kurang dari $4 \mathrm{~cm}$ dan lebih dari $50 \mathrm{~cm}$.

3. Sudut pandang dalam proses tracking yang baik: $0-45^{\circ}$, sedang: $75^{\circ}$, buruk: lebih dari $75^{0}$.

4. Cahaya sangat dibutuh kan dalam proses tracking ini, cahaya yang baik: tidak terlalu terang, sedang: sedikit gelap, buruk: tidak ada cahaya atau cahaya terlalu terang

5. Hanya smartphone yang memiliki spesifikasi dari unity 3D yaitu ARmV 7 saja yang lancar menjalankan aplikasi ini

\section{B. Saran}

Perlu dilakukan penelitian lanjutan dengan penambahan audio atau bahkan video, membuat objek jauh lebih iteraktif dan mengganti marker menjadi lebih menarik mungkin tanpa marker atau markerless dan penambahan pergerakkan objek menggunakan touch.

\section{REFERENSI}

[1] Silas, Johan, (2002), Pembangunan Permukiman dan Prasarana Wilayah.

[2] Magetsari, N. 1992. Kamus Istilah Perpustakaan dan Dokumentasi

[3] Azuma, Ronald T,(Agustus 1997) Journal “A Survey Of Argumented Reality”. Interfaces and Design

[4] Andrew I. Comport. (2006). Real-Time Markerless Tracking forAugmented Reality.

[5] Mario Fernando Rentor (januari, 2013) :Rancang Bangun Perangkat Lunak Pengenalan Motif Batik Berbasis Augmented Reality.

[6] Nazruddin, S. H. (2011). Android: Pemrograman Aplikasi Mobile Smartphone dan Tablet. 